\title{
Commentary: The unliganded glucocorticoid receptor positively regulates the tumor suppressor gene BRCA1 through GABP beta
}

\author{
Hanan Polansky * and Adrian Javaherian \\ The Center for the Biology of Chronic Disease, Valley Cottage, NY, USA
}

Keywords: microcompetition, latent virus, transcription factor, cancer, stress

\section{A commentary on}

The unliganded glucocorticoid receptor positively regulates the tumor suppressor gene BRCA1 through GABP beta by Ritter, H. D., Antonova, L., and Mueller, C. R. (2012). Mol. Cancer Res. 10, 558-569.

OPEN ACCESS

Edited by:

Saleh A. Naser, University of Central Florida, USA

Reviewed by:

John Wayne Rumsey, SSC \& Seminole County Public

Schools, USA

Claudia D. Andl, Vanderbilt University, USA

Alvaro G. Estevez,

University of Central Florida, USA

*Correspondence:

Hanan Polansky,

polydna100@gmail.com

Received: 20 April 2015 Accepted: 02 September 2015 Published: 24 September 2015

Citation:

Polansky H and Javaherian A (2015) Commentary: The unliganded glucocorticoid receptor positively regulates the tumor suppressor gene BRCA1 through GABP beta.

Front. Cell. Infect. Microbiol. 5:66. doi: 10.3389/fcimb.2015.00066
A significant event leading to the development of breast cancer is loss of BRCA1 function. BRCA1 is a tumor suppressor involved in the maintenance of genomic stability and prevention of cell transformation. Many studies showed that stress increases the binding of cortisol to the glucocorticoid receptor (GR) (Ritter et al., 2012). Ritter et al. showed that GR interacts with GABP $\beta$ at the BRCA1 promoter (Ritter et al., 2012). This, in turn, activates BRCA1 expression. The study also showed that addition of hydrocortisone, which binds the GR, eliminates the interaction between GR and GABP $\beta$, causing a deficiency of the GABP transcription factor to the BRCA1 gene, which decreases its expression, and increases the risk of breast cancer (see Figure 1A). We would like to propose a second mechanism by which stress causes a deficiency of the GABP transcription factor involving the presence of certain latent viruses in the cell. This event has been described in 2003 in a book on Microcompetition (Polansky, 2003).

Many viruses consist of a core binding sequence as part of their enhancers, termed the Nbox. When such a virus establishes a latent infection, the viral N-boxes bind the GABP.p300 transcription complex. Furthermore, since this complex is limiting, the viral N-boxes decrease the availability of the complex to cellular genes. As a result, the cellular genes that are stimulated by the GABP.p300 complex produce fewer proteins, and the genes that are suppressed by this complex produce more proteins. The abnormal levels of these cellular proteins induce disease (Polansky, 2003). The term "Microcompetition" describes the relationship between viral and cellular regulatory elements.

It is interesting that many common viruses, which establish a latent infection, have a strong N-box in their promoters/enhancers. These viruses include the Epstein-Barr virus (EBV), Cytomegalovirus (CMV), Herpes Simplex Virus (HSV), Varicella Zoster Virus (VZV), Hepatitis B Virus (HBV), Hepatitis C Virus (HCV), and the Human Papillomavirus (HPV). In fact, the CMV has the strongest promoter/enhancer known to science. In order to estimate the power of the CMV promoter, we will combine the results from a few studies. Results from Liu et al. (2004) can be used to estimate the strength of the CMV promoter/enhancer, which includes the N-box, relative to the strength of the promoter of the cellular platelet-derived growth factor-b chain (PDGF-b) gene. Part B of Figure 1 in Liu et al. reports the expression level driven by the CMV E/P (that is, the CMV enhancer/promoter) vs. those driven by the PDGF-b promoter in a variety of cells, including the COS-7, KB3-1, U251, PC12, and C17.2 cells. A close inspection of the numbers on the y-axis, 


\title{
Stress
}

\author{
A Increased \\ number \\ B Increased \\ Cortisol•GR \\ binding
} latent virus copy

A

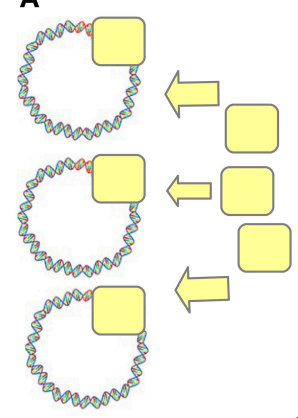

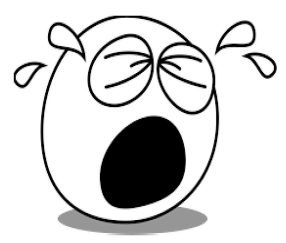

\section{Decreased
GABPß•BRCA1
binding at prom \\ binding at promoter}

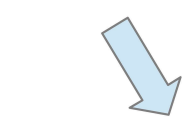

B

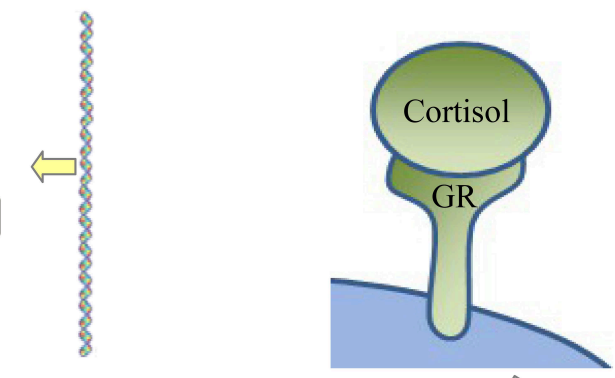

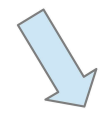

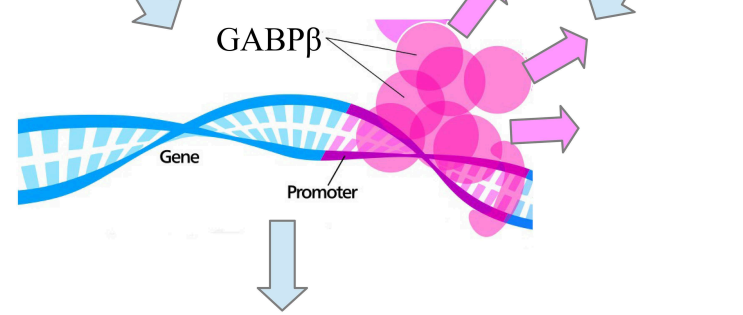

Decreased
BRCA1
expression

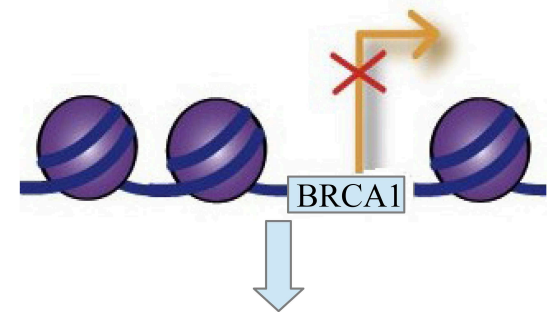

\section{Breast Cancer}

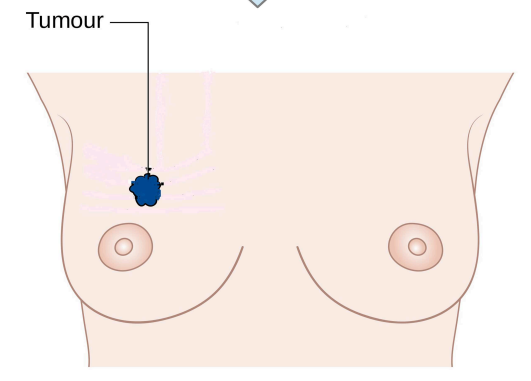

FIGURE 1 | Two pathways initiated by a stress signal lead to breast cancer. One pathway involves an increase in latent viral copy number (A). Another pathway involves an increase in cortisol•GR binding (B). Both events lead to a decrease in GABP $\beta$ binding to the BRCA1 promoter, decrease in BRCA1 expression, and breast cancer.

which are depicted logarithmically, suggests that the CMV $\mathrm{P} / \mathrm{E}$ is about 150 -fold stronger than the PDGF-b promoter. We suspect that the reason for the difference is the much higher affinity that the CMV promoter/enhancer has to the
GABP.p300 transcription complex relative to the PDGF-b promoter. Slobedman and Mocarski showed that during latency, an infected cell harbors about 10 copies of the CMV (Slobedman and Mocarski, 1999). Therefore, the impact of a latent infection 
with the CMV is equivalent to the introduction of 1500 copies of additional PDGF-b genes into the cell. Adam et al. showed that PDGF-b is susceptible to microcompetition with CMV (Adam et al., 1996). Therefore, according to Microcompetition theory, a latent CMV infection would result in a decrease in PDGF-b transcription followed by a decrease in the concentration of the expressed protein in the latently infected cell, ultimately leading to disease.

A number of studies showed the presence of EBV in breast cancer tissue. Mazouni et al. reported that $33.2 \%$ of tumors analyzed contained the BamHIC sub-region of the EBV genome which encodes the Epstein-Barr encoded RNAs. Furthermore, EBV-positive tumors presented with a more aggressive phenotype (Mazouni et al., 2011). Studies have also shown a correlation between HPV and breast cancer. Damin et al. reported HPV DNA detected in $24.75 \%$ of breast carcinomas (Damin et al., 2004). El-Shinawi et al. reported that $78.6 \%$ of

\section{References}

Adam, G. I., Miller, S. J., Ullerås, E., and Franklin, G. C. (1996). Cell-type-specific modulation of PDGF-b regulatory elements via viral enhancer competition: a caveat for the use of reference plasmids in transient transfection assays. Gene 178, 25-29. doi: 10.1016/0378-1119(96)00318-6

Damin, A. P., Karam, R., Zettler, C. G., Caleffi, M., and Alexandre, C. O. (2004). Evidence for an association of human papillomavirus and breast carcinomas. Breast Cancer Res. Treat. 84, 131-137. doi: 10.1023/B:BREA.0000018411.89667.0d

El-Shinawi, M., Mohamed, H. T., El-Ghonaimy, E. A., Tantawy, M., Younis, A., Schneider, R. J., et al. (2013). Human cytomegalovirus infection enhances NFkB/p65 signaling in inflammatory breast cancer patients. PLOS ONE 8:e55755. doi: 10.1371/journal.pone.0055755

Liu, B. H., Wang, X., Ma, Y. X., and Wang, S. (2004). CMV enhancer/human PDGF-Beta promoter for neuron-specific transgene expression. Gene Ther. 11, 52-60. doi: 10.1038/sj.gt.3302126

Mazouni, C., Fina, F., Romain, S., Ouafik, L., Bonnier, P., Brandone, J.-M., et al. (2011). Epstein-Barr virus as a marker of biological aggressiveness in breast cancer. Br. J. Cancer 104, 332-337. doi: 10.1038/sj.bjc.6606048 inflammatory breast cancer (IBC) tissues were HCMV-DNA positive, suggesting a possible role for HCMV in the pathobiology of IBC (El-Shinawi et al., 2013).

Stress increases viral copy number in a cell infected with a latent virus. This increase in viral copy number causes an increase in GABP bound to viral enhancers. Microcompetition ensues, decreasing the availability of GABP to the BRCA1 promoter, resulting in GABP transcription factor deficiency. This, in turn, decreases BRCA1 expression and increases the risk of breast cancer (see Figure 1B).

Due to the prevalence of latent viral infection, we believe that viral induced transcription factor deficiency is highly important, and has a significant impact on an individual's general health. Most individuals harbor a latent viral infection exposing them to transcription factor deficiency. Therefore, these individuals are at risk of diseases that can be triggered by such deficiency, including cancer.
Polansky, H. (2003). Microcompetition with Foreign DNA and the Origin of Chronic Disease. Rochester, NY: CBCD Publishing.

Ritter, H. D., Antonova, L., and Mueller, C. R. (2012). The unliganded glucocorticoid receptor positively regulates the tumor suppressor gene $B R C A 1$ through GABP Beta. Mol. Cancer Res. 10, 558-569. doi: 10.1158/15417786.MCR-11-0423-T

Slobedman, B., and Mocarski, E. S. (1999). Quantitative analysis of latent human cytomegalovirus. J. Virol. 73, 4806-4812.

Conflict of Interest Statement: The authors declare that the research was conducted in the absence of any commercial or financial relationships that could be construed as a potential conflict of interest.

Copyright (C) 2015 Polansky and Javaherian. This is an open-access article distributed under the terms of the Creative Commons Attribution License (CC BY). The use, distribution or reproduction in other forums is permitted, provided the original author(s) or licensor are credited and that the original publication in this journal is cited, in accordance with accepted academic practice. No use, distribution or reproduction is permitted which does not comply with these terms. 